\title{
EL ORGANO POSITIVO EN EL CLAUSTRO DE SOR JUANA INES DE LA CRUZ. UN CASO ÚNICO EN SU GÉNERO EN MÉXICO
}

\author{
Michael Drewes
}

Parece que hoy en día los órganos positivos, instrumentos pequeños, sin pedalera y con un número limitado de registros en su mayoría de flautas cerradas, utilizados en su época para el acompañamiento de coros o en la música de cámara, son bastante poco comunes en México. De hecho, el que se halla en el Claustro de Sor Juana Inés de la Cruz, al lado del templo de San Jerónimo en la ciudad de México, es tal vez el único representante de su género, dado que otro similar en la iglesia de Santo Domingo de Zacatecas, todavía documentado por Pál Kélemen, ${ }^{1}$ no se ubica ya en su lugar.

El órgano positivo en cuestión, que a la sazón se localiza en el Claustro de Sor Juana Inés de la Cruz, data de mediados o de fines del siglo XVII y estuvo antes en el Conservatorio Nacional de Música, según relata el propio Pál Kélemen al haberlo visto ahí, probablemente antes de 1951.2 Pertenecía al compositor Salvador Moreno,, quien lo donó al Museo Nacional de Antropología e Historia, que a su vez lo suministró para su exhibición en el coro alto del templo de San Jerónimo, en 1964. ${ }^{4}$ En dicho lugar todavía se encontró el 27 de octubre de 1977, cuando se hizo el levantamiento; sus componentes fueron inventariados el 28 de

1 Pál Kélemen, Baroque and Rococo in Latin America, Volume 2, Illustrations. New York, Dover Publications, 1967. La lámina 152 muestra a) Santo Domingo, Zacatecas, y b) ciudad de México, donde se reconoce el órgano positivo que actualmente está en el Claustro de Sor Juana Inés de la Cruz.

2 Pál Kélemen, op. cit., Volume 1, Text. New York, 1967, p. 229. Como la primera edición data de 1951, esta suposición se justifica.

3 Al hacerse el levantamiento, se halló una tarjeta pegada al mueble, que decía: "Organo de los principios del siglo XVII. Donación del compositor Salvador Moreno." El autor pudo conversar personalmente con Salvador Moreno el 16 de no. viembre de 1981, en ocasión de la conferencia dictada por el doctor Diego Angulo Iñiguez acerca de la evolución pictórica de Bartolomé Esteban Murillo, en el Palacio de Minería en la ciudad de México.

4 Francisco de la Maza, El sepulcro de Sor Juana Inés de la Cruz. México, 1967, p. 27, apud Francisco de la Maza, Arquitectura de los coros de monjas en México. México, 1983. 
noviembre del mismo año, el 30 se fotografiaron todas sus partes, ${ }^{5}$ y el 2 de diciembre se empacó en dos grandes cajas de triplay flejadas. ${ }^{6}$

El día 27 de octubre de $1982^{7}$ tuve la oportunidad de ver y probar el instrumento restaurado en el taller del señor Joachim Wesslowski. Al fecharse tentativamente en 1670 , se puede afirmar que sea tal vez el organo más antiguo en el continente americano. Consta de un armario que alberga caja de viento, arca de ventillas, flautas y teclado. Este último se alcanza al abrirse las dos hojas frontales, mientras que la puerta trasera sirve de acceso para afinar y entonar las flautas.

Detrás del armario se hallan los dos fuelles de cuña, accionados a mano. Todo el conjunto se apoya sobre una armazón de madera. Al tratarse de un órgano para acompañar coros o para dar el fundamento armónico en pequeños conjuntos instrumentales a modo de "continuo", tiene un ámbito reducido $\mathrm{y}$ pocos registros que, al ser agudos, requieren el apoyo de un instrumento más grave como viola da gamba, violoncello, fagot o contrabajo.

La tesitura va en octava corta, del $\mathrm{DO}_{2}, \mathrm{RE}_{2}, \mathrm{MI}_{2}, \mathrm{FA}_{2}, \mathrm{SOL}$, $\mathrm{LA}_{2}$, $\mathrm{SIb}_{2}, \mathrm{SI}_{2}, \mathrm{DO}_{3}$ al $\mathrm{LA}_{5}$ en 42 teclas. La separación entre bajo y soprano ocurre entre el $\mathrm{DO}_{4}$ y $\mathrm{DO} \#_{4}$. Los registros se accionan por deslizadores que se empujan hacia adentro para la posición abierta, muy al contrario de lo que sucede normalmente en un órgano.

En la resturación, llevada a cabo bajo la asesoría del doctor Dirk A. Flentrop de Holanda, deliberadamente no se aprovecharon todas las flautas originales, sino sólo aquellas que permitían seguir un criterio de unidad, ya que las flautas encontradas sugerían la procedencia de diversos fabricantes, o incluso, de otros instrumentos. ${ }^{8}$ No se logró reconstruir el registro de lengïeta. Viajes de estudio efectuados para ver el órgano

- Estas fotografías fueron tomadas por José Luis Espinosa Cervantes.

6 Véase anexo, Inventario de las piezas del órgano de San Jerónimo, para el permiso de exportación temporal, redactado el 10 de enero de 1980 . Se pensaba enviar el instrumento a los talleres de Flentrop Orgelbouw B. V. en Holanda para su restauración, hasta que se optó por hacer los trabajos en México con el señor Joachim Wesslowski Schlüter, maestro organero que hiciera su aprendizaje en la prestigiosa empresa de Von Beckerath en Hamburgo.

7 Debido a las dificultades de encontrar un local para el taller de restauración de órganos en México, se perdió mucho tiempo. El problema se resolvió cuando el St. Wesslowski lo estableció en su casa, habiendo aportado todo el equipo necesario de su propio peculio.

8 Se sugirió entonces exponer los tubos no aprovechados en una vitrina al lado del órgano. 
similar mencionado de Zacatecas, fueron inútiles al no hallarse dicho instrumento en el lugar.

Los registros son:

Lado izquierdo (bajo)

Del $\mathrm{DO}_{2}, \mathrm{RE}_{2}, \mathrm{MI}_{2}, \mathrm{FA}_{2}$, $\mathrm{SOL}_{2}, \mathrm{LA}_{2}, \mathrm{SIb}_{2}, \mathrm{SI}_{2}$ al $\mathrm{DO}_{4}$ en 21 teclas:

Violón 4'

Flautado 2'

Docena $11 / 3^{\prime}$

Quincena 1'

Diez septena $4 / 5^{\prime}$

Diez novena $1 / 3^{\prime}$

Veintidocena $1 / 2^{\prime}$
Lado derecho (tiple)

Del DO\#, al LA en 21 teclas:

Violón 4'

Flautado 2'

Docena 2 2/3'

Quincena 2'

Diez septena $13 / 5^{\prime}$

Diez novena $11 / 3^{\prime}$

Veintidocena 1'

Como el órgano es pequeño y se trató de ahorrar espacio, se usó como registro más grave uno de flautas cerradas, ya que "el sonido fundamental emitido por un tubo cerrado $n_{c}$ es la octava grave del sonido fundamental emitido por un tubo abierto $n_{a}$ de la misma longitud." ${ }^{\prime} \mathrm{Co}^{-}$ mo consecuencia, el registro denominado "Violón" da un sonido correspondiente a un tubo abierto de cuatro pies de longitud, utilizando uno cerrado de dos pies. El "Flautado" suena a la octava superior, según el hecho de que "la frecuencia correspondiente al sonido fundamental que puede producir un tubo, varía inversamente a la longitud del mismo", lo que vale también para la "Quincena" y la "Veintidocena". La "Docena" y la "Diez novena" dan la quinta en vez de la fundamental, y la "Diez septena", la tercera. Utilizándose todos los registros simultáneamente, se obtendría una mixtura completa, aunque en la práctica no es aconsejable aprovechar un órgano en toda su capacidad, en vista de que se perdería la presión del aire, lo que iría en detrimento de la afinación y la sonoridad. En este caso de San Jerónimo se lograrían buenos resultados con recurrir a tres o cuatro registros a la vez como máximo.

En los registros transpositores a la quinta, tercera y octava superiores,

9 Tírso de Olarzábal, Acústica musical y organología. Buenos Aires, Ricordi Americana, 1954, p. 113.

10 lbídem. 
como "Docena", "Quincena", "Diez septena", "Diez novena" y "Veintidocena", se emplearon para el lado del bajo flautas a la mitad de la longitud con respecto a las del tiple, con el simple pretexto de ahorrar espacio. Esto desde luego afecta la sonoridad, ya que la escala cromática del bajo suena igual a la del tiple, ocasionándose una ruptura entre el $\mathrm{DO}_{4}$ y $\mathrm{DO}_{4}$; pero esta inconveniencia puede subsanarse al agregarse la fundamental del "Violón" o del "Flautado".

Se probó el órgano el mismo día 27 de octubre de 1982, con fuelles conectados a un pequeño ventilador que inyectaba el aire en uno de ellos, habiéndose ensayado piezas de Johann Pachelbel (1653-1706) y de Johann Krieger (1651-1735). Además se tomaron fotografías del instrumento terminado. Sus dimensiones están consignadas en planos que obran en el archivo de la Subdirección de Obras de Restauración, de la Secretaría de Desarrollo Urbano y Ecología.

La octava corta'del lado del bajo del teclado dificulta en algo la ejecución. Sin embargo, esto puede ser superado al familiarizarse el organista a mayor profundidad con el instrumento. El órgano quedó instalado el día 5 de noviembre de 1982 en un local del Claustro de Sor Juana Inés de la Cruz, y fue inaugurado oficialmente en esa misma fecha.

Cabe mencionar que en el cuadro La adoración de la sagrada forma, pintado por Claudio Coello (1642-1693) en 1685 y que se ubica en la sacristía de El Escorial, se advierte al lado del enfermizo rey Carlos II (1665-1700) y sus cortesanos un órgano positivo con dos fuelles, tocado por un monje, detrás del cual cantan y tocan una chirimía y un fagot otros frailes. Puede considerarse el instrumento representado un equivalente al que aquí nos ocupa, aunque su caja no sea de ensamblado, sino de madera tallada y dorada. ${ }^{11}$

En los apartamentos de la infanta Clara Eugenia se encuentra un órgano de procesión que data probablemente de 1589 , construido por un miembro de la familia Brebos y que cuenta con teclado de 38 teclas en octava corta y seis registros alojados en primorosa caja tallada. ${ }^{12}$

En el museo diocesano del claustro de la antigua catedral de Salamanca, España, se exhibe el "realejo de Salinas", llamado así porque pertenecía a Francisco Salinas, maestro de música de la Universidad de 1567

\footnotetext{
11 Comentado e ilustrado en J. Pijoán, Historia del arte, tomo 7. México, Salvat Editores de México, S.A., 1972, pp. 86-87.

12 Bernard Sonaillon, L'orgue. Instruments et musiciens. Paris, Office du Livre. Éditions Vilo, 1984, p. 203.
} 
DOI: http://dx.doi.org/10.22201/iie.18703062e.1989.60.2378
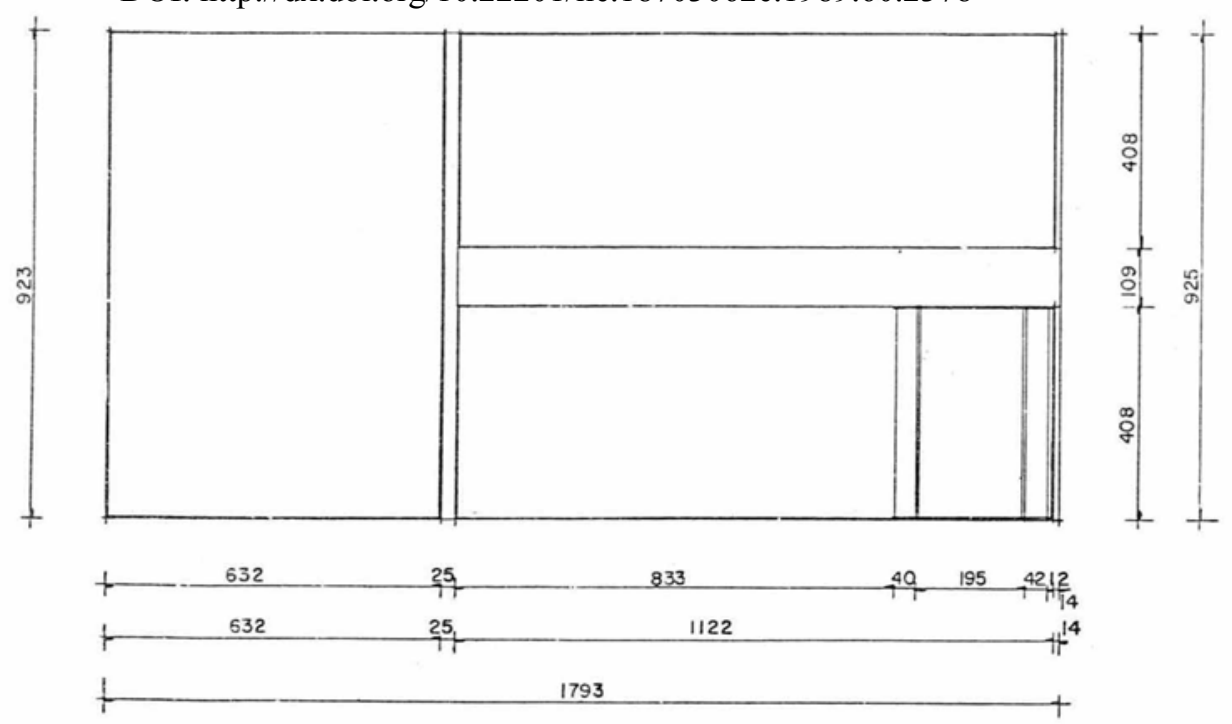

1. Planta del órgano. El conjunto consistente en armario y dos fuelles sobre un armazón.
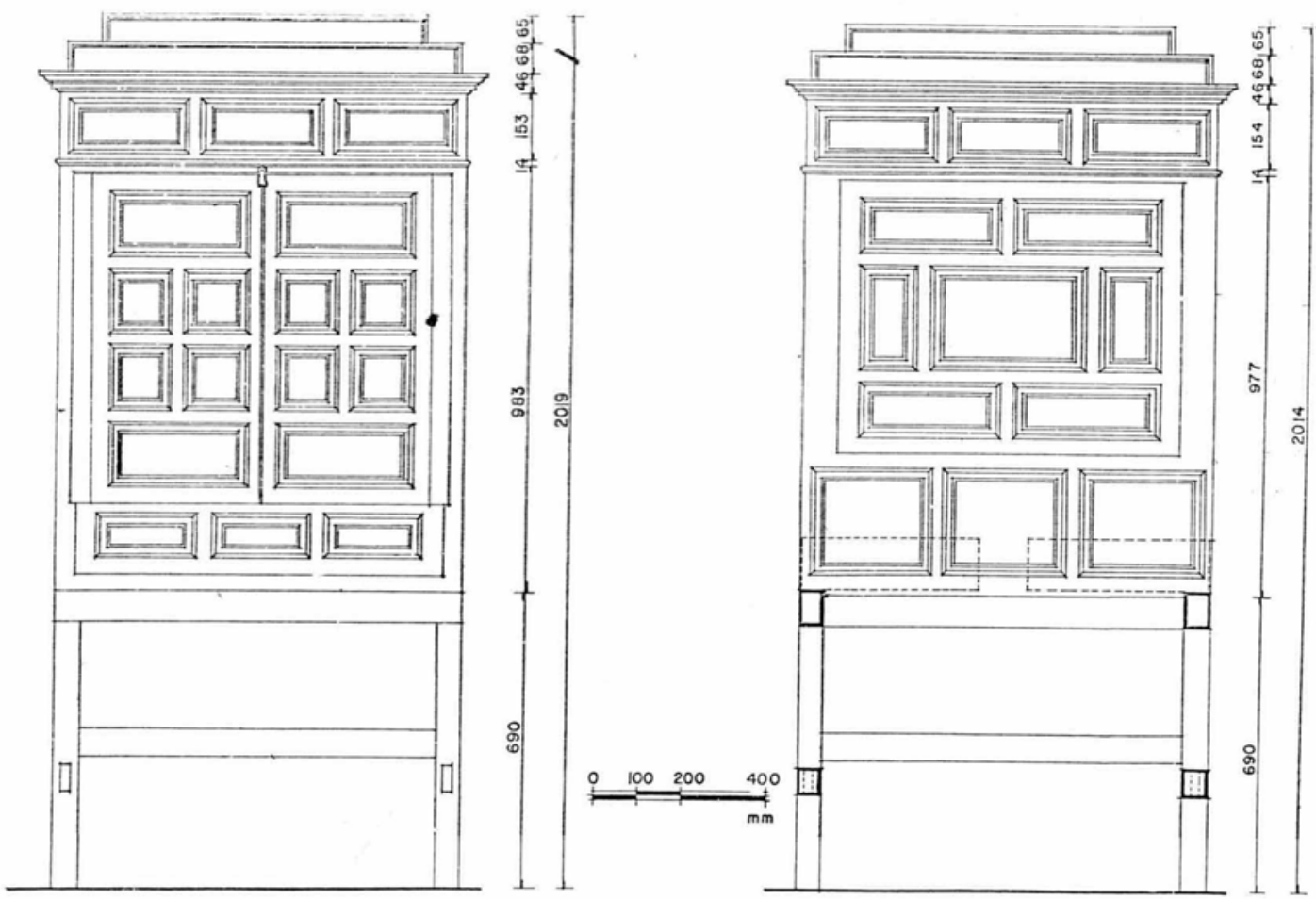

2. Alzados frontal y posterior del órgano. 
DOI: http://dx.doi.org/10.22201/iie.18703062e.1989.60.2378

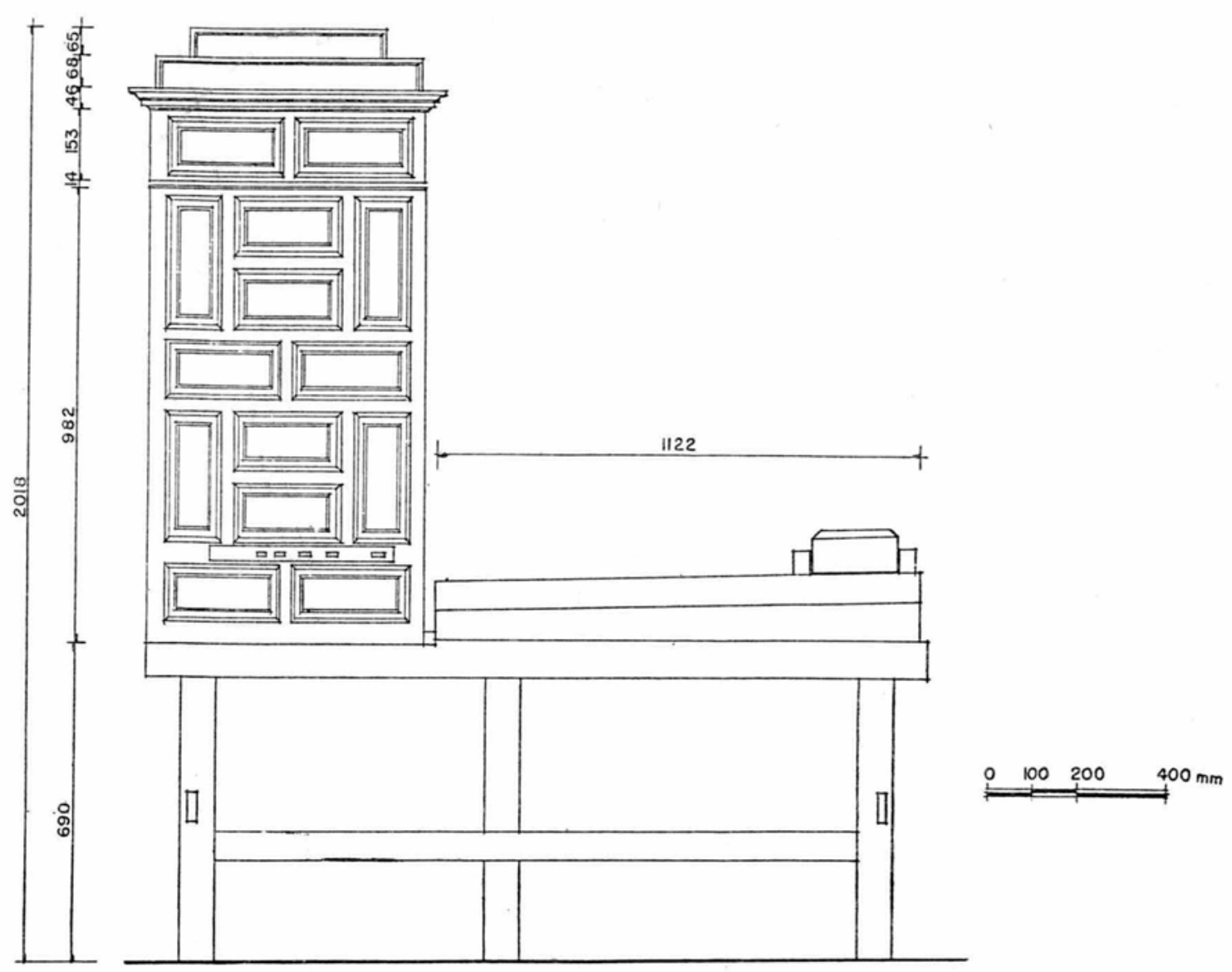

3. Alzado lateral del órgano. 
DOI: http://dx.doi.org/10.22201/iie.18703062e.1989.60.2378

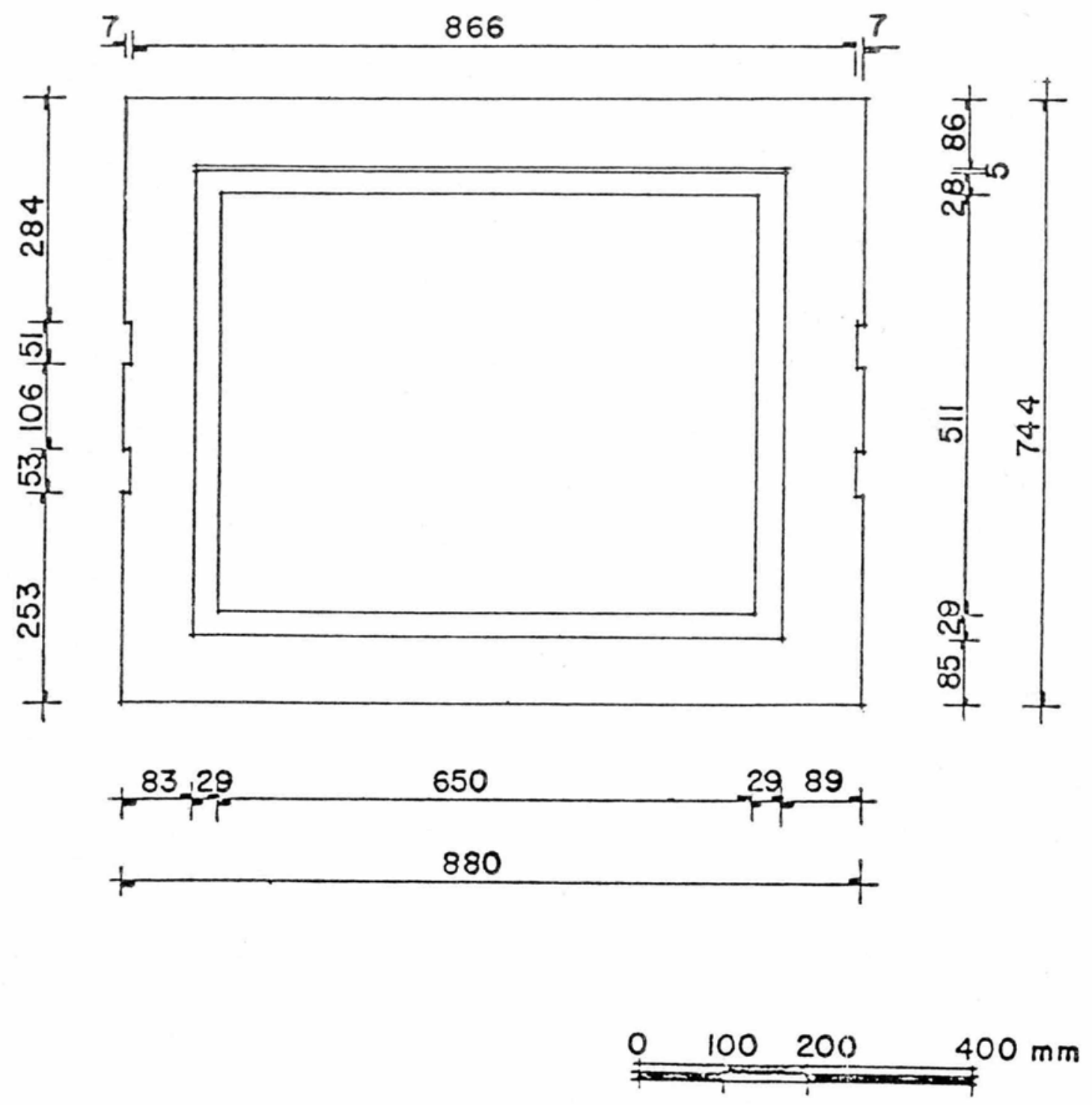

4. El marco de la pantalla de tela y su contramarco. 
DOI: http://dx.doi.org/10.22201/iie.18703062e.1989.60.2378

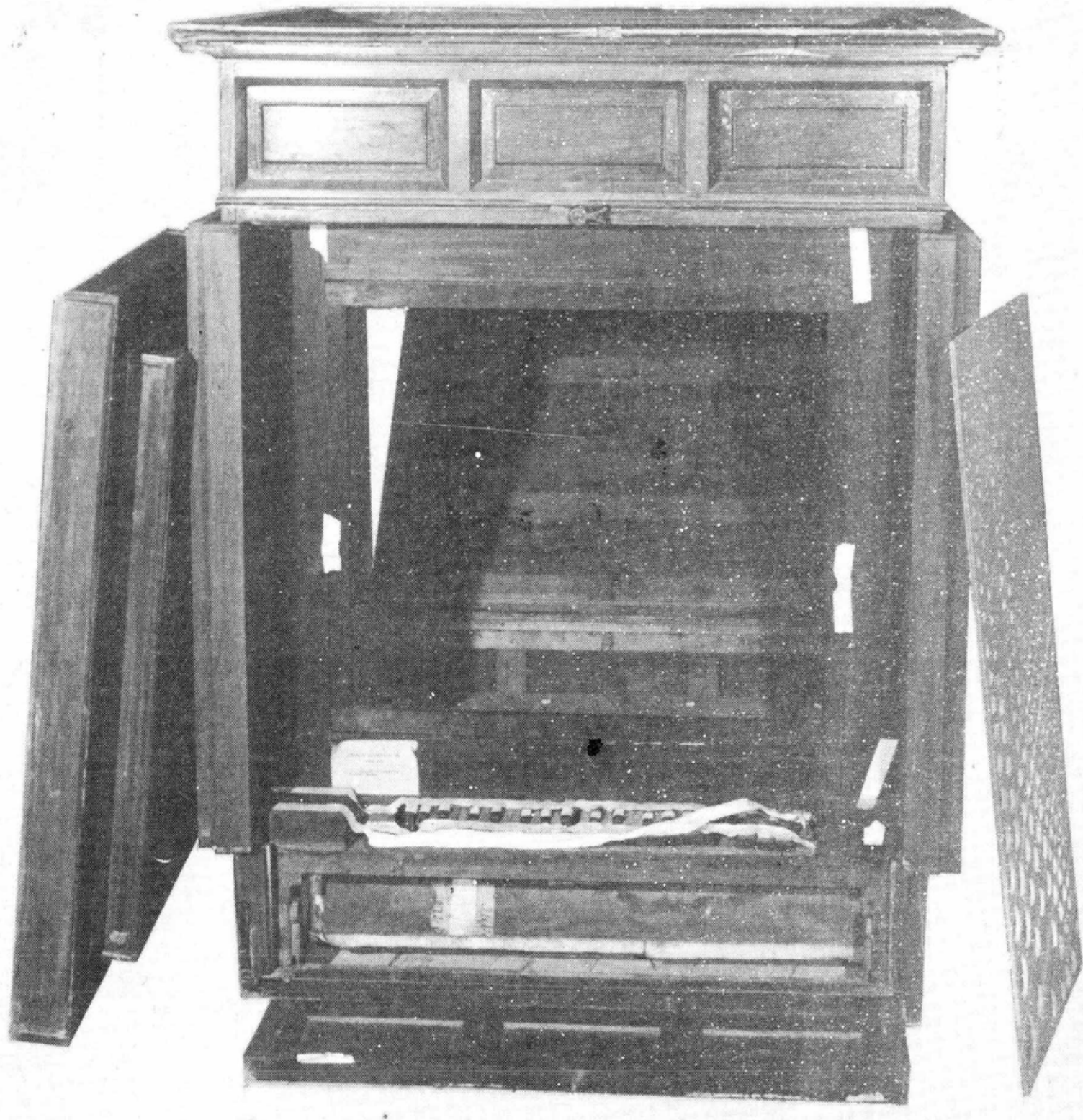

5. El armario con las puertas abiertas. 
DOI: http://dx.doi.org/10.22201/iie.18703062e.1989.60.2378

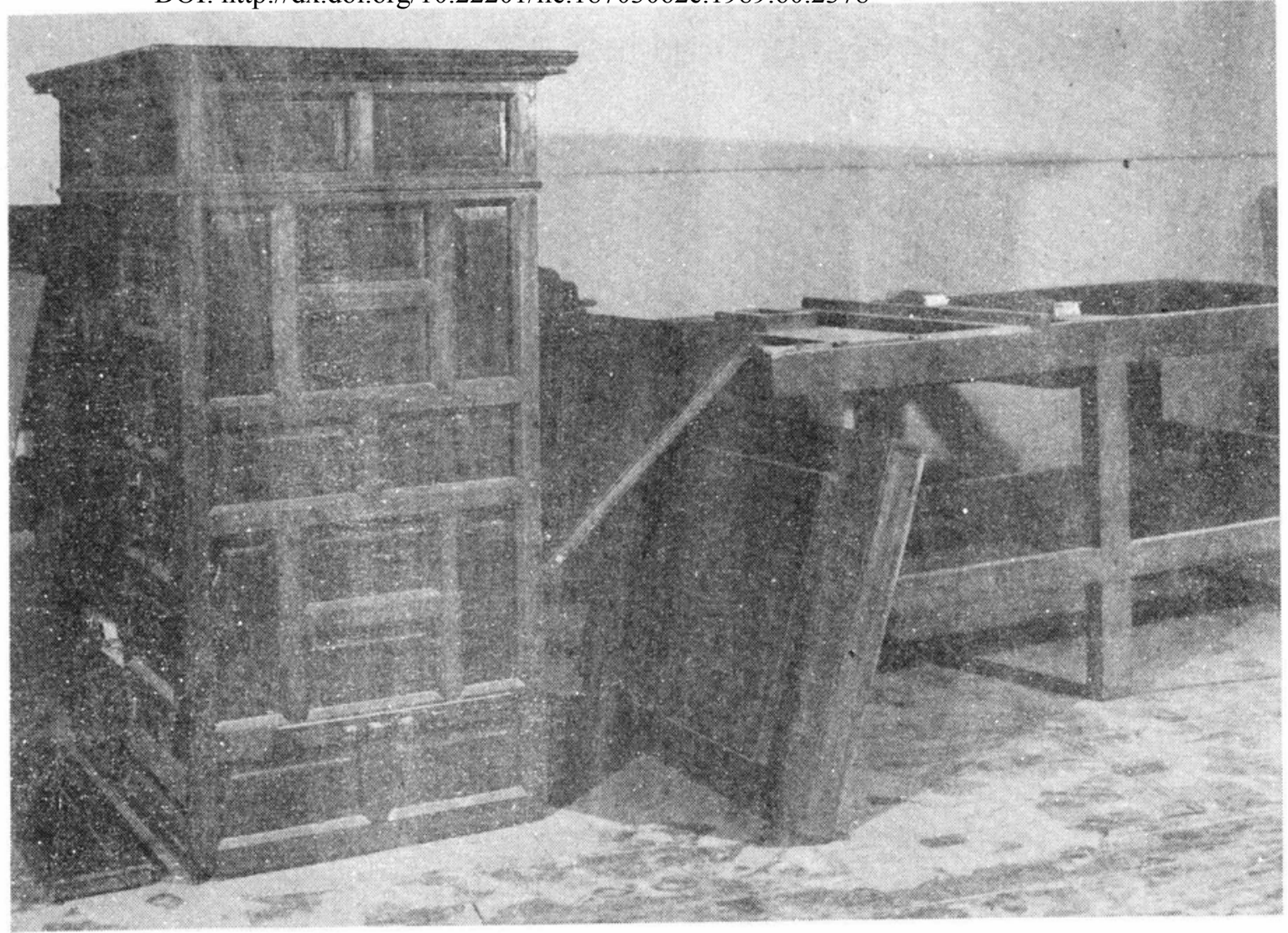

6. El órgano desmantelado antes de su empaque para el envío al taller de restauración. 


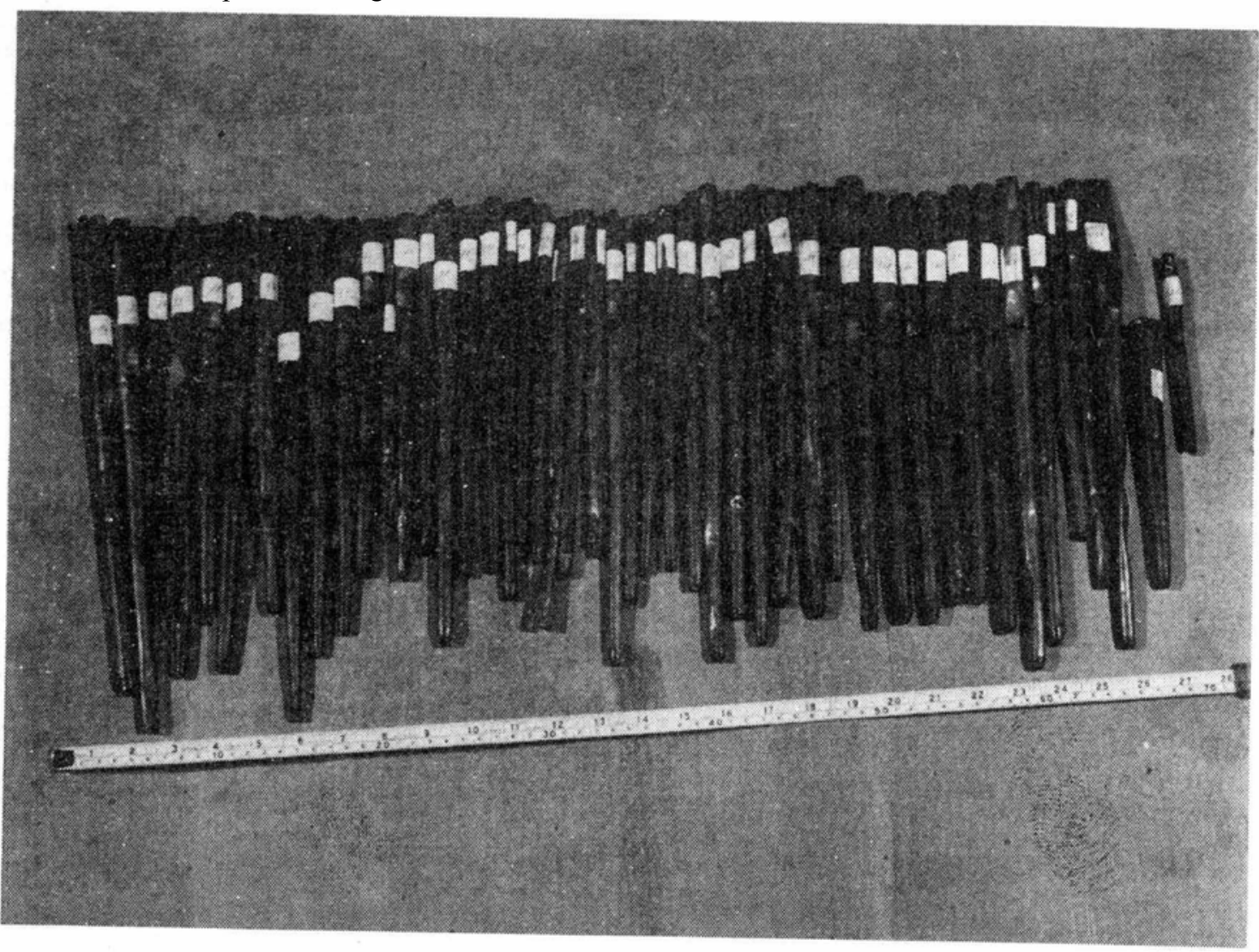

7. Una parte de las flautas halladas en el órgano. 
DOI: http://dx.doi.org/10.22201/iie.18703062e.1989.60.2378

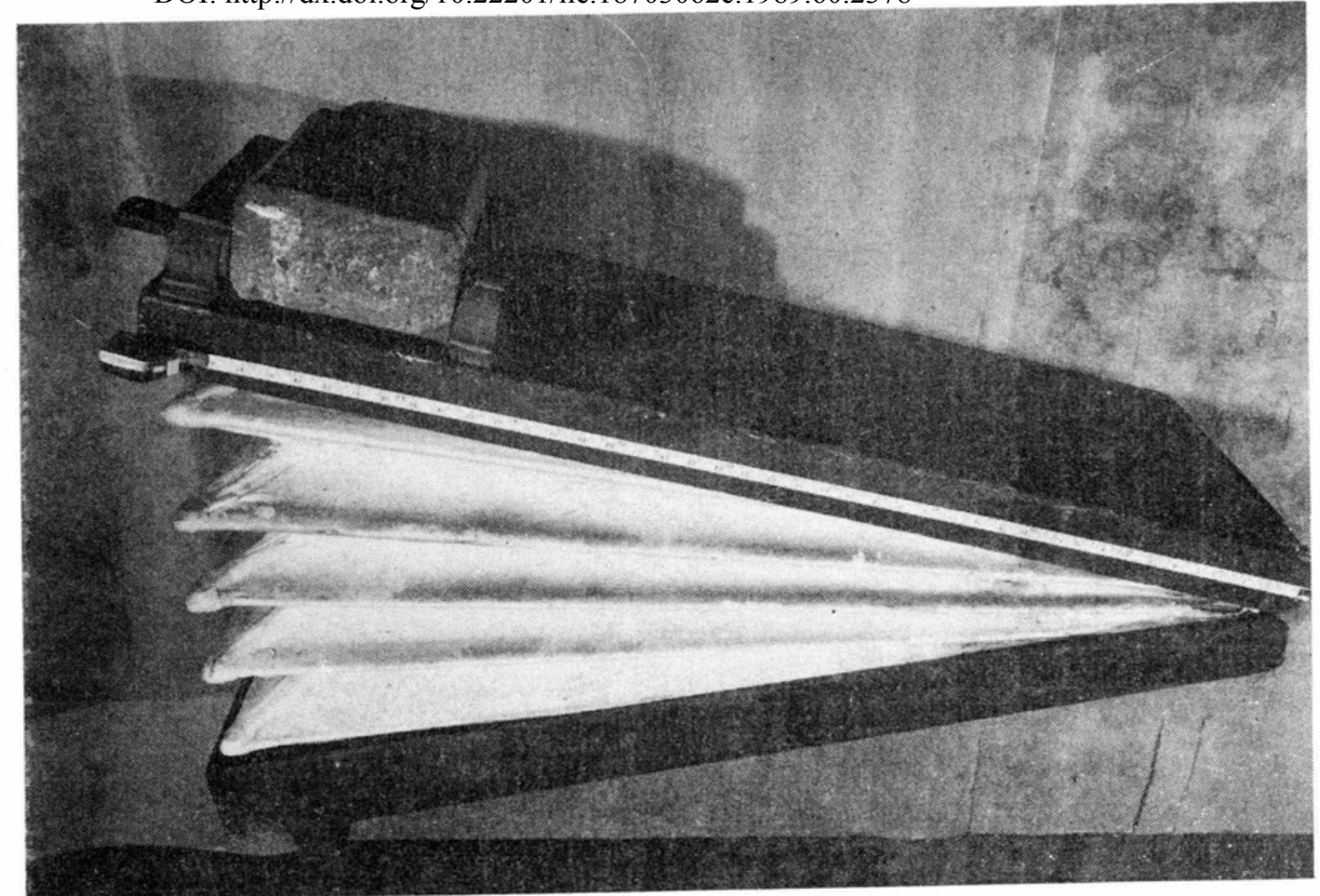

8. Uno de los fuelles con su contrapeso. 
DOI: http://dx.doi.org/10.22201/iie.18703062e.1989.60.2378
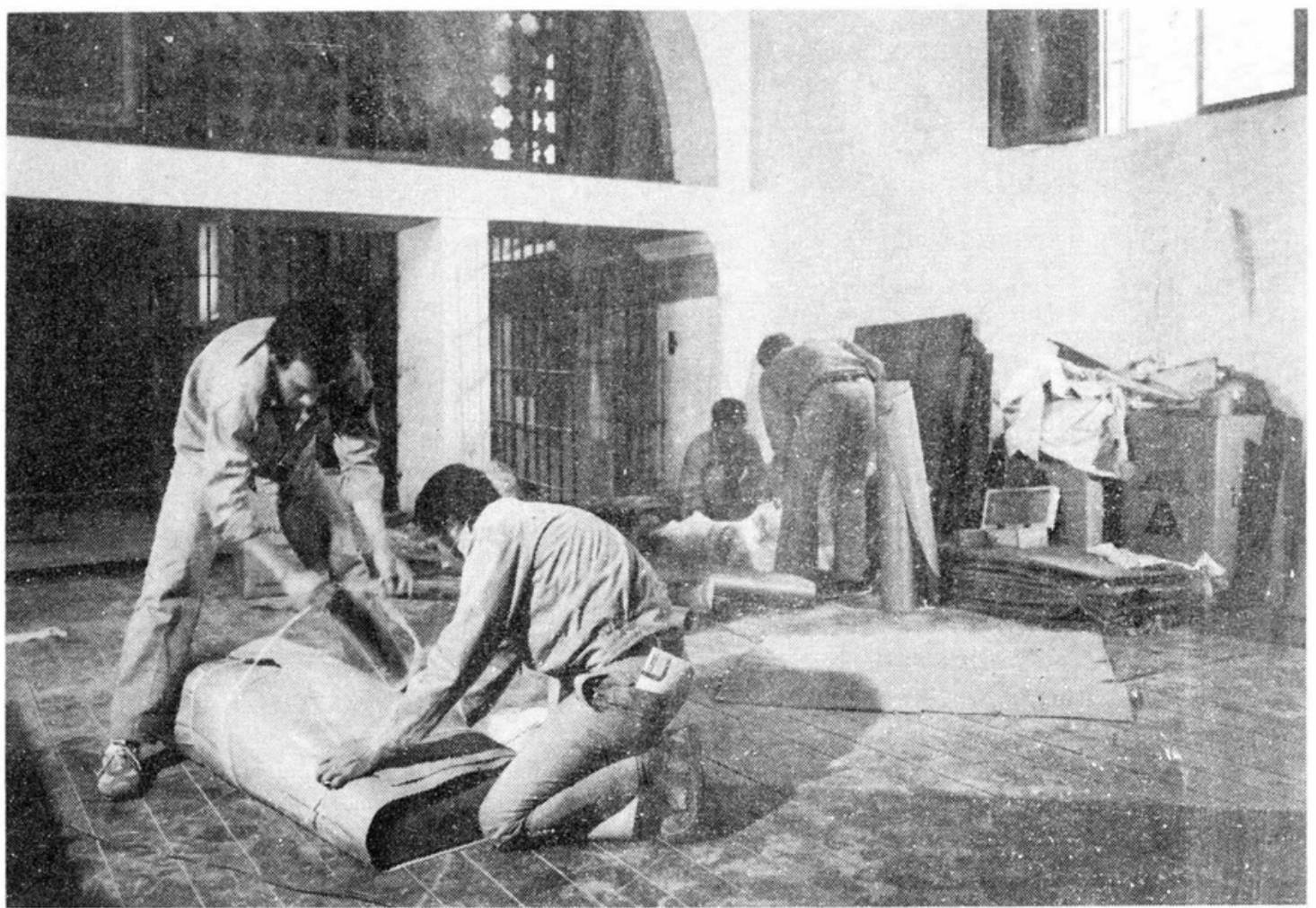

9. 2 de diciembre de 1977, empaque del órgano para su envío al taller de restauración. 
a 1588 . Fechado tentativamente en 1569 , consta de un teclado de 42 teclas en octava corta y posee ocho registros subdivididos en bajo y tiple. ${ }^{13}$ Podemos preciarnos de poseer ahora en México un prototipo original del siglo XVII de este género poco común de órgano positivo, restaurado fielmente y en condiciones de ser tocado para revivir la música de la época.

13 Idem, p. 202. 


\section{INVENTARIO DE LAS PIEZAS DEL ORGANO \\ DE SAN JERONIMO, PARA EL PERMISO \\ DE EXPORTACION TEMPORAL}

Una caja de triplay, flejada, de $1.90 \mathrm{~m} \times 1.04 \mathrm{~m} \times 0.90 \mathrm{~m}$, que contiene:

Caja No. 1: 76 flautas, hechas de una aleación de plomo y estaño, numeradas del 1 al 76 , de las cuales;

40 flautas, cerradas, numeradas del 1 al 40 , y

36 flautas abiertas, numeradas del 41 al 76 .

Caja No. 2: 54 flautas, hechas de una aleación de plomo y estaño, numeradas del 77 al 130, de las cuales;

53 flautas abiertas, numeradas del 77 al 130 ,

1 pie de flauta, numerado con el 129.

Caja No. 4: 1 fuelle, de $1.122 \mathrm{~m} \times 0.408 \mathrm{~m} \times 0.147 \mathrm{~m}$.

Caja No. 5: 1 fuelle, de $1.122 \mathrm{~m} \times 0.408 \mathrm{~m} \times 0.147 \mathrm{~m}$.

Uno de los fuelles tiene un contrapeso de piedra, de

$0.408 \mathrm{~m} \times 0.195 \mathrm{~m} \times 0.095 \mathrm{~m}$.

Caja No. 6: 1 armazón de madera, de $0.925 \mathrm{~m} \times 1.793 \mathrm{~m} \times 0.69 \mathrm{~m}$.

Una caja de triplay, flejada, de $0.87 m \times 1.15 m \times 1.35 \mathrm{~m}$, marcada "Caja No. 3", que contiene:

1 armario de madera con labor de ensamble, de $0.925 \mathrm{~m} \times 0.632 \mathrm{~m} \times$ $1.195 \mathrm{~m}$, con dos puertas abatibles de $0.385 \mathrm{~m} \times 0.763 \mathrm{~m}$, hacia el frente, y una puerta abatible, de $0.771 \mathrm{~m} \times 0.635 \mathrm{~m}$, hacia atrás; que contiene una caja de viento para cinco registros, un teclado de 42 teclas blancas y negras, del $\mathrm{DO}_{2}$ al $\mathrm{LA}_{5}$, y caja de válvulas.

1 parrilla soporte de flautas, de triplay, con agujeros recortados.

1 marco de madera, de $0.708 \mathrm{~m} \times 0.568 \mathrm{~m}$, que sirve para sostener una pantalla de tela.

1 contramarco de madera, de $0.88 \mathrm{~m} \times 0.744 \mathrm{~m}$, que sirve para sostener el marco anterior.

1 tapa escalonada, de madera, de $0.902 \mathrm{~m} \times 0.608 \mathrm{~m} \times 0.133 \mathrm{~m}$, para apoyarse sobre la cornisa del armario. 